\begin{tabular}{|c|l|}
\hline Title & Hydrogen isotope ratios in lunar rocks indicate delivery of cometary water to the Moon \\
\hline Author(s) & Greenwood, James P.; Itoh, Shoichi; Sakamoto, Naoya; W arren, Paul; Tay lor, Lawrence; Y urimoto, Hisay oshi \\
\hline Citation & $\begin{array}{l}\text { Nature Geoscience, 4(2), 79-82 } \\
\text { https://doi.org/40.1038NGEO1050 }\end{array}$ \\
\hline Issue Date & 2011-02 \\
\hline Doc URL & http://hdl.handle.net/2115/46873 \\
\hline Type & article (author version) \\
\hline File Information & NG4_2_79-82.pdf \\
\hline
\end{tabular}

Instructions for use 


\section{Hydrogen isotope ratios in lunar rocks and the delivery of cometary water to the Moon}

Water plays a critical role in the evolution of planetary bodies ${ }^{1}$, and determination of the amount and sources of lunar water has profound implications for our understanding of the history of the Earth-Moon system. During the Apollo program, the lunar samples were found to be devoid of indigeneous water ${ }^{2,3}$. The severe depletion of lunar volatiles ${ }^{4}$, including water, has long been seen as strong support for the giant-impact origin of the Moon $^{5}$. Recent studies have found water in lunar volcanic glasses ${ }^{6}$ and in lunar apatite ${ }^{7-9}$, but the sources of lunar water have not been determined. Here we report ion microprobe measurements of water and hydrogen isotopes in the hydrous mineral apatite, found in crystalline lunar mare basalts and highlands rocks collected during the Apollo missions. We find significant water in apatite from both mare and highlands rocks, indicating a role for water during all phases of the Moon's magmatic history. Variations of hydrogen isotope ratios in apatite suggest the lunar mantle, solar wind protons, and comets as possible sources for water in lunar rocks and imply a significant delivery of cometary water to the Earth-Moon system shortly after the Moon-forming impact.

The $\mathrm{D} / \mathrm{H}$ of water can discriminate between various water reservoirs on Earth and in the solar system and can also be used as an important test for terrestrial contamination. For example, during the Apollo program there were several reports of water or hydrous minerals in lunar samples ${ }^{10,11}$, but the $\mathrm{D} / \mathrm{H}$ of this water was indistinguishable from Earth's atmospheric water vapor, consistent with terrestrial contamination ${ }^{2,3}$. The $\delta \mathrm{D}$ value $^{12}$ of Earth's water ranges from $\sim-500 \%$ o to $\sim+100 \%$, with the majority of values in the $-200 \%$ to $+50 \%$ range; ocean water does not deviate greatly from a mean $\delta \mathrm{D}$ value of $0 \%{ }^{13}$. The range in $\delta \mathrm{D}$ values of the Earth's water is primarily influenced by atmospheric water circulation, wherein evaporation in the equatorial regions leads to a progressive depletion in $\mathrm{D}$ as water condenses towards the poles, leading to a latitudinal dependence of $\delta \mathrm{D}$ (and ${ }^{18} \mathrm{O} /{ }^{16} \mathrm{O}$ ) values of water, known as the 'meteoric water line, ${ }^{14}$. The $\delta \mathrm{D}$ value of $\sim-100 \%$ o for the Earth's mantle is indistinguishable from the majority of meteoritic material, suggesting the Earth's mantle water was either inherited from accreting material, or the inner solar system had a similar and small range of $\delta \mathrm{D}$ during planet formation ${ }^{15}$. In contrast, the $\delta \mathrm{D}$ of the present day solar system exhibits a much larger range (-1000\%o to $>+100,000 \%$ o), from the H-rich Sun to the D-enriched venusian atmosphere $^{15}$.

Measurements of water content and $\delta \mathrm{D}$ using secondary ion mass spectrometry (SIMS) in the hydrous mineral apatite $\left[\mathrm{Ca}_{5}\left(\mathrm{PO}_{4}\right)_{3}(\mathrm{~F}, \mathrm{Cl}, \mathrm{OH})\right]$ have been very useful in distinguishing between crustal and magmatic sources of water in Martian basaltic meteorites $^{16,17}$. We have developed a new SIMS technique that includes two-dimensional ion imaging using a stacked CMOS-type active pixel sensor (SCAPS) (see Methods). With this method, we have obtained the first measurements of $\mathrm{D} / \mathrm{H}$ of water in lunar apatite. 
Apatite was analyzed in a range of lunar lithologic types from several landing sites. Lunar lithologic types include mare basalts (Apollo 11: 10044; Apollo 12: 12039 and 12040; Apollo 14: 14053; Apollo 17: 75055), breccias (12013 and 14305,94), and an alkali anorthosite highlands clast $(14305,303)$ (see Supplementary Information for detailed description of Apollo samples). In the mare basalts studied here, apatite is associated with late-stage crystallization features, including such phases as K-Si-rich glass, pyroxferroite, fayalite, silica, K-Ba-rich feldspar and mesostasis. Apatite grain fragments were studied from the late-stage matrix regions of the two breccias. We also studied one apatite grain from a pristine intrusive alkali anorthosite highlands clast that had up to $2.8 \%$ modal phosphate.

A SCAPS ${ }^{1} \mathrm{H}$ image of an apatite grain from high-Ti mare basalt 10044 clearly shows the apatite grain to be enriched in water $\left({ }^{1} \mathrm{H}\right)$ relative to surrounding mineral grains (Figure 1). Water contents of apatite grains in mare basalts range from 0 to $6050 \mathrm{ppm}$ $\mathrm{H}_{2} \mathrm{O}$ (Figure 2 and Table S5). These are the highest water contents measured in lunar samples $^{6-9}$. Both high-Ti (10044 and 75055) and low-Ti (12039 and 14053) mare basalts contain apatite grains with abundant water. We analyzed five apatite grains in 12039, and found large inter-crystalline variations in water content (Table S5). One apatite grain from 12039 overlaps in water content with those of basalts 10044, 75055, and 14053 (Figure 2 and Table S5). This suggests similar water contents for the source magmas of these mare basalts (from three landing sites), which are separated in both space (100's $\mathrm{km})$ and time ( $\sim 00$ million years). The range of water contents between individual apatite grains in 12039 can be understood as due to differences in the crystallization extent of isolated melt pockets, as water is a highly incompatible element in basaltic magmas, and apatite in the mare basalts forms very late in the crystallization sequence $(>95 \% \text { crystallization })^{18}$.

The $\delta \mathrm{D}$ values of water in apatite grains from mare basalts 10044, 12039, and 75055 range from $+391 \%$ to $+1010 \%$ (Figure 2 and Table S5). These $\delta \mathrm{D}$ values are more D-enriched than any terrestrial water and support the assertion that we have analyzed indigenous lunar water in these samples. The $\delta \mathrm{D}$ values are variable within individual apatite grains of 12039 (Figure 2, Table S5), but the water contents of these same apatite grains are homogeneous. The lack of correlation between $\mathrm{H}_{2} \mathrm{O}$ and $\delta \mathrm{D}$ of individual lunar apatite grains (Figure 2, Table S5) would seem to rule out an origin for elevated $\delta \mathrm{D}$ of lunar water by the processes of degassing of water or hydrogen, subsolidus diffusion of hydrogen, or dehydration reactions, as these processes should lead to a correlation of $\delta \mathrm{D}$ and $\mathrm{H}_{2} \mathrm{O}$ (see Supplementary Information). Contributions to the elevated $\delta \mathrm{D}$ of lunar water by spallogenic production of $\mathrm{D}$ on the lunar surface by cosmic radiation are inferred to be minimal, as we see no correlation of $\delta \mathrm{D}$ and cosmic-ray exposure ages of samples studied here (see Supplementary Information). Minor element zonation of $\mathrm{F}, \mathrm{Cl}, \mathrm{SiO}_{2}$, and $\mathrm{FeO}$ in lunar apatite grains suggests that $\delta \mathrm{D}$ may have been decreasing with crystallization in two of the four mare apatite grains large enough for multiple SIMS analyses, but this is tenuous with the present dataset (see Supplementary Information). Micro-scale variability of $\delta \mathrm{D}$ values in the hydrous mineral amphibole from mantle xenoliths ${ }^{19}$ and the Montserrat volcano ${ }^{20}$ shows that intra-grain and intergrain hydrogen isotopic heterogeneity can be preserved during volcanic processes on Earth. If process-related effects on the $\delta \mathrm{D}$ of lunar magmas can be largely ruled out, then the range of $\delta \mathrm{D}$ in the mare basalts requires contributions from different isotopic 
reservoirs, and it also requires that these water components were not homogenized during magma generation, ascent, and eruption/emplacement. The micro-scale variability of water and $\delta \mathrm{D}$ in 12039 indicates at least two water sources were involved, a low $\delta \mathrm{D}$ and a high $\delta \mathrm{D}$ component.

Not all mare basalt apatite contains significant water. The only apatite grain we were able to analyze in low-Ti olivine basalt 12040 has very low water content (Figure 2 and Table S5). Of the Apollo 12 basalt suite, 12040 is considered one of the slowestcooled samples $^{21}$, suggesting the magma of 12040 may have underwent extensive degassing of water. Significant degassing of water has recently been suggested for 12040 based on $\mathrm{Cl}$ isotope composition of apatite ${ }^{22}$. Apatite grain fragments in the late-stage matrix regions of breccia samples 12013 and 14305,94 were also found to have very low water. The thermal history experienced by these apatite grains during the impact brecciation event may have dehydrated these grains if they were originally hydrous.

Two analyses of an apatite grain in a highlands alkali anorthosite clast $(14305,303)$ show that this grain contains $80 \pm 10 \mathrm{ppm} \mathrm{H}_{2} \mathrm{O}$ (Figure 2 and Table S5). The alkali suite rocks represent an episode of highlands magmatism that mostly postdates initial ferroan anorthosite crust formation $(\sim 4.4 \mathrm{Ga}$ to $3.9 \mathrm{Ga}$ ) but precedes mare basalt volcanism $(\sim 3.85 \text { to } 1.0 \mathrm{Ga})^{23}$. Our results indicate that water was present during the generation of the alkali suite rocks. Mantle sources of water for this intrusive rock could be the volatile-rich and incompatible-element-rich materials resulting from magma ocean crystallization that were either assimilated or were involved in the generation of the alkali suite magmas. Another potential source of water could be from the assimilation of volatile-rich and altered lower lunar crust. The $\delta \mathrm{D}$ values of highlands apatite range from $+240 \%$ o to $+340 \%$ (Figure 2 and Table S5). This may represent the low $\delta$ D water reservoir in the lunar interior. An elevated $\delta \mathrm{D}$ of the lunar mantle relative to Earth could result from several processes. One possibility is that the Earth-Moon system was able to diffusively equilibrate its volatiles shortly after the Moon-forming impact ${ }^{24}$, and the original $\delta \mathrm{D}$ of the Moon was similar to that of the Earth's mantle ( $\delta \mathrm{D} \sim-100 \%$ ). If so, then the $\delta \mathrm{D}$ of lunar water could have been fractionated to the values seen in this highlands rock ( $\delta \mathrm{D} \sim+240 \%$ o to $+340 \%$ ) during hydrodynamic escape of hydrogen during the Moon's formation. A second possibility involves addition of D-enriched material, such as cometary water or meteoritic/interstellar organic compounds ${ }^{15}$, to an early Moon that inherited its water from the Earth's mantle ( $\delta \mathrm{D} \sim-100 \%$ o).

Apatite grains in mare basalt 14053 have the lowest $\delta \mathrm{D}$ values measured in this study (-172 to $-215 \%$; Figure 2 and Table S5), and could be representative of a low $\delta \mathrm{D}$ water reservoir in the lunar interior. The low $\delta \mathrm{D}$ values of apatite grains in 14053 can be readily explained by the rocks unique petrologic history, which involved implantation of solar wind protons at the lunar surface followed at some later time by metamorphism in an impact blanket ${ }^{25}$. This would imply that basalt 14053 had a more D-rich signature prior to emplacement on the lunar surface and suggests that this sample should not be used to estimate lunar mantle water contents ${ }^{9}$.

The heavier $\delta \mathrm{D}$ values measured in apatite from mare basalt 12039 are similar to those measured for comets Hale-Bopp, Hyakutake and $\mathrm{P} / \mathrm{Halley}^{15}$, suggesting that comets could be a significant source of the high $\delta \mathrm{D}$ water reservoir of the Moon (Figure 3). There are only a few analyses of meteorites ${ }^{15}$ that overlap with the range of $\delta \mathrm{D}$ seen in 
the mare basalts (with the exception of basalt 14053), suggesting comets as the most likely source for the high $\delta \mathrm{D}$ water component.

The cometary water component seen in the lunar samples would appear to be significant and is likely inherited from a heterogeneous lunar mantle or an altered volatile-rich lower lunar crust. A third possibility would be from the assimilation of lunar regolith that has been enriched in water from impact delivery of cometary water to the lunar surface ${ }^{26}$. Delivery of asteroidal water to the regolith would also seem to be a possibility, but an estimate of the asteroidal+cometary flux of $\mathrm{D}$ and $\mathrm{H}$ to the Moon (from implanted $\mathrm{D}$ and $\mathrm{H}$ in lunar soil grains: $\delta \mathrm{D}=+470 \%{ }^{27}$ ) is too low to explain the majority of our D-enriched apatite grains. Assimilation of volatile-enriched regolith may be a possibility for the extrusive mare lavas but is unlikely to explain the elevated $\mathrm{D}$ of the intrusive highlands alkali anorthosite clast 14305,303. An interior source for the high $\delta \mathrm{D}$ component of lunar water would seem to require that the majority of water contributed by comets to the lunar magma ocean occurred during the short time interval between the Moon-forming impact and solidification of the lunar highlands crust. This scenario predicts a significant input of cometary water to the Earth at this time as well. The Denrichment of the Earth's oceans relative to the Earth's mantle could result from such an early addition of cometary water to the $\operatorname{Earth}^{28}$. Future work on lunar samples may constrain this early delivery of cometary water to the Earth-Moon system.

\section{METHODS}

Lunar samples were obtained from NASA and were rock thin sections mounted on silica glass slides with carbon-based epoxy. Samples were carbon-coated for electron and ion microbeam analyses. Ion microscope analyses were conducted at Hokkaido University using a modified Cameca ims 1270 ion microscope with a SCAPS ion imager to undertake two complementary ion beam techniques. Quantitative data for $\delta \mathrm{D}$ and $\mathrm{H}_{2} \mathrm{O}$ of apatite were obtained in ion microprobe spot analysis mode. For spot analysis, a Cs ${ }^{+}$ primary beam of $20 \mathrm{keV}$ was focused to a beam spot of $\sim 10 \mu \mathrm{m}$ on the surface of the sample with a beam current of $12 \mathrm{nA}$. Secondary ions generated from the center of the primary beam irradiation area of $2 \times 2 \mu \mathrm{m}^{2}$ were collected using a field aperture. ${ }^{1} \mathrm{H}$ and ${ }^{2} \mathrm{D}$ were collected sequentially in an electron multiplier for $2 \mathrm{~s}$ and $20 \mathrm{~s}$, respectively, in peak-jumping mode, at $\mathrm{M} / \Delta \mathrm{M}$ about 2300 . Ion imaging of ${ }^{1} \mathrm{H}$ was collected in the SCAPS detector, which allowed for semi-quantitative data to be obtained (e.g. Fig. 1b) and spatial distribution of ${ }^{1} \mathrm{H}$ in lunar samples. A 20-sample airlock system, which allowed samples to be pumped at $3 \times 10^{-8}$ torr for $>3$ days before analysis, was important to remove terrestrial adsorbed water contamination prior to ion microprobe spot analyses. Apatite standards for ion microprobe analyses were analyzed for $\delta \mathrm{D}$ and $\mathrm{H}_{2} \mathrm{O}$ at Yale University using continuous flow isotope ratio mass spectrometry. Electron microprobe analyses were conducted at Yale University using a JEOL JXA-8530F "Hyperprobe" FEG electron microprobe operated at $15 \mathrm{kV}$ with appropriate mineral standards. A10 nA beam current, a defocused beam of $10-15 \mu \mathrm{m}$, and $10 \mathrm{~s}$ count times were used to minimize electron beam damage of apatite. Electron imaging was conducted before ion microscope analysis, but quantitative electron microprobe analysis was never undertaken prior to ion microprobe analysis, in order to minimize damage of lunar samples. Detailed methods are available in the Supplementary Information. 
1. Albaréde F. Volatile accretion history of the terrestrial planets and dynamic implications. Nature 461, 1227-1233 (2009).

2. Epstein, S. \& Taylor, H. P., Jr. The isotopic composition and concentration of water, hydrogen, and carbon in some Apollo 15 and 16 soils and in the Apollo 17 orange soil. In Proc. $4^{\text {th }}$ Lunar Sci. Conf., Vol. 2, 1559-1575 (1973).

3. Epstein, S. \& Taylor, H. P., Jr. D/H and ${ }^{18} \mathrm{O} /{ }^{16} \mathrm{O}$ ratios of $\mathrm{H}_{2} \mathrm{O}$ in the "rusty" breccia 66095 and the origin of "lunar water". In Proc. $5^{\text {th }}$ Lunar Sci. Conf., Vol. 2, 18391854 (1974).

4. Taylor, S. R., Taylor, G. J., \& Taylor, L. A. The Moon: A Taylor perspective. Geochim. Cosmochim. Acta 70, 5904-5918 (2006).

5. Canup, R. M. \& Asphaug, E. Origin of the Moon in a giant impact near the end of the Earth's formation. Nature 412, 708-712 (2001).

6. Saal, A. E., Hauri, E. H., Lo Cascio, M., Van Orman, J. A., Rutherford, M. C. \& Cooper R. F. Volatile content of lunar volcanic glasses and the presence of water in the Moon's interior. Nature 454, 192-195 (2008).

7. McCubbin, F. M. et al. Nominally hydrous magmatism on the Moon. Proc. Nat. Acad. Sci. 27, 11223-11228 (2010).

8. McCubbin, F. M., Steele, A., Nekvasil, H., Schnieders, A., Rose, T., Fries, M., Carpenter, P. K. \& Jolliff, B. L. Detection of structurally bound hydroxyl in fluorapatite from Apollo mare basalt 15058,128 using TOF-SIMS. Am. Mineral. 95, 1141-1150 (2010).

9. Boyce, J. W., Liu, Y., Rossman, G. R., Guan Y., Eiler, J. M., Stolper, E. M. \& Taylor L. A. Lunar apatite with terrestrial volatile abundances. Nature 466, 466-469 (2010).

10. Friedman, I., O’Neil, J. R., Adami, L. H., Gleason, J. D. \& Hardcastle, K. Water, Hydrogen, Deuterium, Carbon, Carbon-13, and Oxygen-18 content of selected lunar material. Science 167, 538-540 (1970).

11. Taylor, L. A., Mao, H. K. \& Bell, P. M. "Rust” in the Apollo 16 rocks in Proc. $4^{\text {th }}$ Lunar Sci. Conf., Vol. 1, 829-839 (1973).

12. Due to small variations in $\mathrm{D} / \mathrm{H}$ on Earth, the $\mathrm{D} / \mathrm{H}$ is generally reported as per mil deviations from a standard (standard: VSMOW-Vienna Standard Mean Ocean Water $): \delta \mathrm{D}=\left\{\left[(\mathrm{D} / \mathrm{H})_{\text {sample }} /(\mathrm{D} / \mathrm{H})_{\text {VsMow }}\right]-1\right\} \times 1000$.

13. Sheppard, S. M. F. Characterization and isotopic variations in natural waters. In Stable isotopes in High Temperature Geological Processes (eds. J. W. Valley, H. P. Taylor, Jr., J. R. O’Neil) Reviews in Mineralogy, Vol. 16, 165-183 (1986).

14. Craig, H. Isotopic variations in meteoric waters. Science 133, 1702-1703 (1961).

15. Robert, F. Solar system Deuterium/Hydrogen ratio. In Meteorites and the Early Solar System II (eds. D. Lauretta and H. Y. McSween, Jr.) Univ. Arizona Press, Tucson 341-352 (2006).

16. Watson, L. L., Hutcheon, I. D., Epstein, S. \& Stolper, E. M. Water on Mars: Clues from Deuterium/Hydrogen and water contents of hydrous phases in SNC meteorites. Science 265, 86-90 (1994).

17. Greenwood, J. P., Itoh, S., Sakamoto, N., Vicenzi, E. P. \& Yurimoto, H. Hydrogen isotope evidence for loss of water from Mars through time. Geophys. Res. Lett. 35, L05203 (2008). 
18. Papike, J. J., Ryder, G. \& Shearer, C. K. Lunar Samples. In Planetary Materials (ed. J. J. Papike) Reviews in Mineralogy, Vol. 36, 5-01-5-234 (1998).

19. Deloule, E., Albaréde, F. \& Sheppard, S. M. F. Hydrogen isotope heterogeneities in the mantle from ion probe analysis of amphiboles from ultramafic rocks. Earth Planet. Sci. Lett. 105, 543 (1991).

20. Harford, C. L. \& Sparks, R. S. J. Recent remobilisation of shallow-level intrusions on Montserrat revealed by hydrogen isotope composition of amphiboles. Earth Planet. Sci. Lett. 185, 285-297 (2001).

21. Rhodes, J. M., Blanchard, D. P., Dungan, M. A., Brannon, J. C. \& Rodgers K. V., Chemistry of Apollo 12 mare basalts: Magma types and fractionation processes. In Proc. Lunar Sci. Conf. $8^{\text {th }} 1305-1338$ (1977).

22. Sharp, Z. D., Shearer, C. K., McKeegan, K. D., Barnes, J. D. \& Wang Y. Q. The chlorine isotope composition of the Moon and implications for an anhydrous mantle. Science 329, 1050-1053 (2010).

23. Shearer, C. K. \& Papike, J. J. Magmatic evolution of the Moon. Am. Mineral. 84, 1469-1494 (1998).

24. Pahlevan, K. \& Stevenson, D. J. Equilibration in the aftermath of the lunar-forming giant impact. Earth Planet. Sci. Lett., 262, 438-449 (2007).

25. Taylor, L. A., Patchen, A., Mayne, R. G. \& Taylor, D-H. The most reduced rock from the moon, Apollo 14 basalt 14053: Its unique features and their origin. Am. Mineral. 89, 1617-1624 (2004).

26. Ong, L., Asphaug, E. I., Korycansky, D. \& Coker, R. F. Volatile retention from cometary impacts on the Moon. Icarus 207, 578-589 (2010).

27. Hashizume, K., Chaussidon, M., Marty, B. \& Robert, F. Solar wind record on the Moon: Deciphering presolar from planetary nitrogen. Science 290, 1142-1145 (2000).

28. Kokubu, N., Mayeda, T. \& Urey, H. C. Deuterium content of minerals, rocks, and liquid inclusions from rocks. Geochim. Cosmochim. Acta 21, 247-256 (1961).

Acknowledgements We thank F. M. McCubbin and F. Robert for constructive reviews, M. Gilmore and W. Herbst for comments on an earlier version of this manuscript, M. Rutherford and A. Basilevsky for discussion, G. Olack and J. Eckert for technical assistance, and Wesleyan University (J.P.G.) and Monkasho (H.Y.) for support.

Author Contributions J.P.G., S.I., N.S., \& H.Y. performed all ion microscopy. J.P.G. conducted all electron microscopy and measurements of water and $\mathrm{D} / \mathrm{H}$ in apatite standards via continuous flow mass spectrometry. All authors contributed to writing of the manuscript.

Additional Information The authors declare no competing financial interests. Supplementary Information accompanies this paper at www.nature.com/naturegeoscience. Reprints and permissions information is available online at www.npg.nature.com/reprintsandpermissions. Correspondence and requests for materials should be addressed to J.P.G. (jgreenwood@wesleyan.edu). 


\section{Figure Legends}

Figure 1. Backscatter electron image (top) and SCAPS ${ }^{1} \mathrm{H}$ image (bottom) of apatite grain 5 of 10044,12. (Top): Apatite (Ap) is texturally associated with many late-stage crystallization minerals, such as fayalite (Fa), pyroxferroite (Pyf), K-Ba-rich feldspar (KBa), hedenbergite $(\mathrm{Hd})$, iron sulfide $(\mathrm{FeS})$, a silica phase (Si), and finely intergrown mesostasis (Meso) composed of plagioclase (Pg) and silica. The location of the SCAPS image is outlined by the white rectangle. (Bottom): SCAPS ${ }^{1} \mathrm{H}$ image of apatite, mesostasis, pyroxferroite, K-Ba-rich feldspar, and cracks. Cracks are high in hydrogen (and are white in the image). The $\mathrm{D} / \mathrm{H}$ of cracks are low and indicative of terrestrial adsorbed water (see Table S5). A K-Ba-rich feldspar grain included in the apatite is cut by a crack containing high hydrogen. The apatite grain has more hydrogen than the included K-Ba-rich feldspar or the pyroxferroite and mesostasis that the apatite is in contact with in this image.

Figure 2. $\delta \mathrm{D}\left(\%\right.$ ) vs. $\mathrm{H}_{2} \mathrm{O}$ (wt.\%) of lunar apatite measured in this study. Three apatite grains are essentially dry $(12040,211 ; 12013,148 ; 140305,94)$, and two of these have $\delta D$ that are difficult to distinguish from terrestrial water. Error bars are $2 \sigma$.

Figure 3. $\delta \mathrm{D}$ plot of the solar system. D/H of water is shown, with the exception of the outer planets and the protosolar estimate, which are $\mathrm{H}_{2}$. The venusian atmosphere and IDPs have extreme D-enrichment due to escape of water from the venusian atmosphere and interstellar water, respectively. Several chondrite data in the literature overlap with the lunar data (excluding 14053), but the majority do not ${ }^{15}$. Mean $\delta \mathrm{D}$ for bulk

carbonaceous chondrite water and ordinary chondrite chondrule and clay water are shown here. Comet data appear to have a similar range to the high $\delta \mathrm{D}$ lunar analyses. Sources of data (ref. 15 and references therein, refs. 16, 17, and J. Greenwood, unpub. data for Mars $\mathrm{OH})$. 

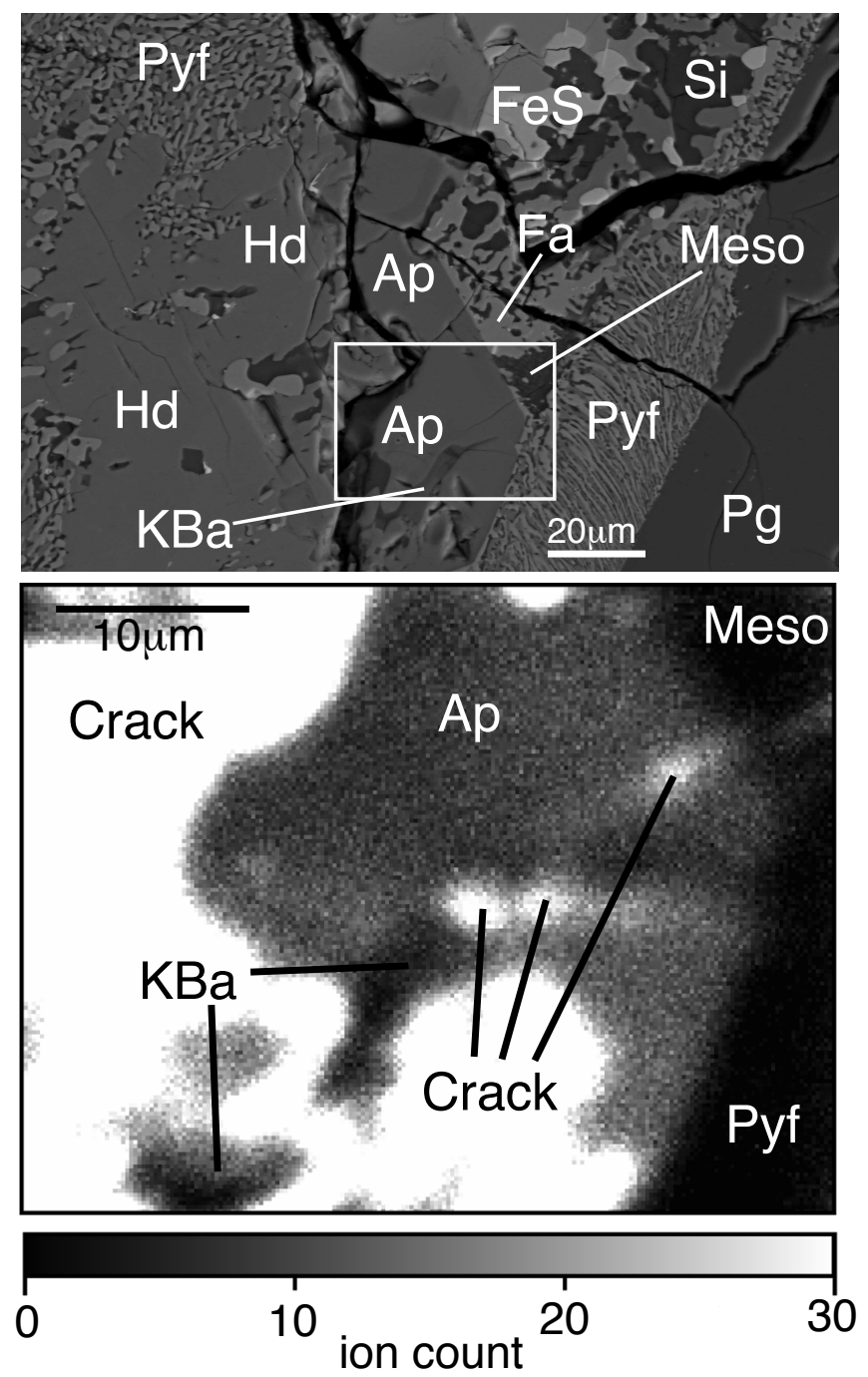


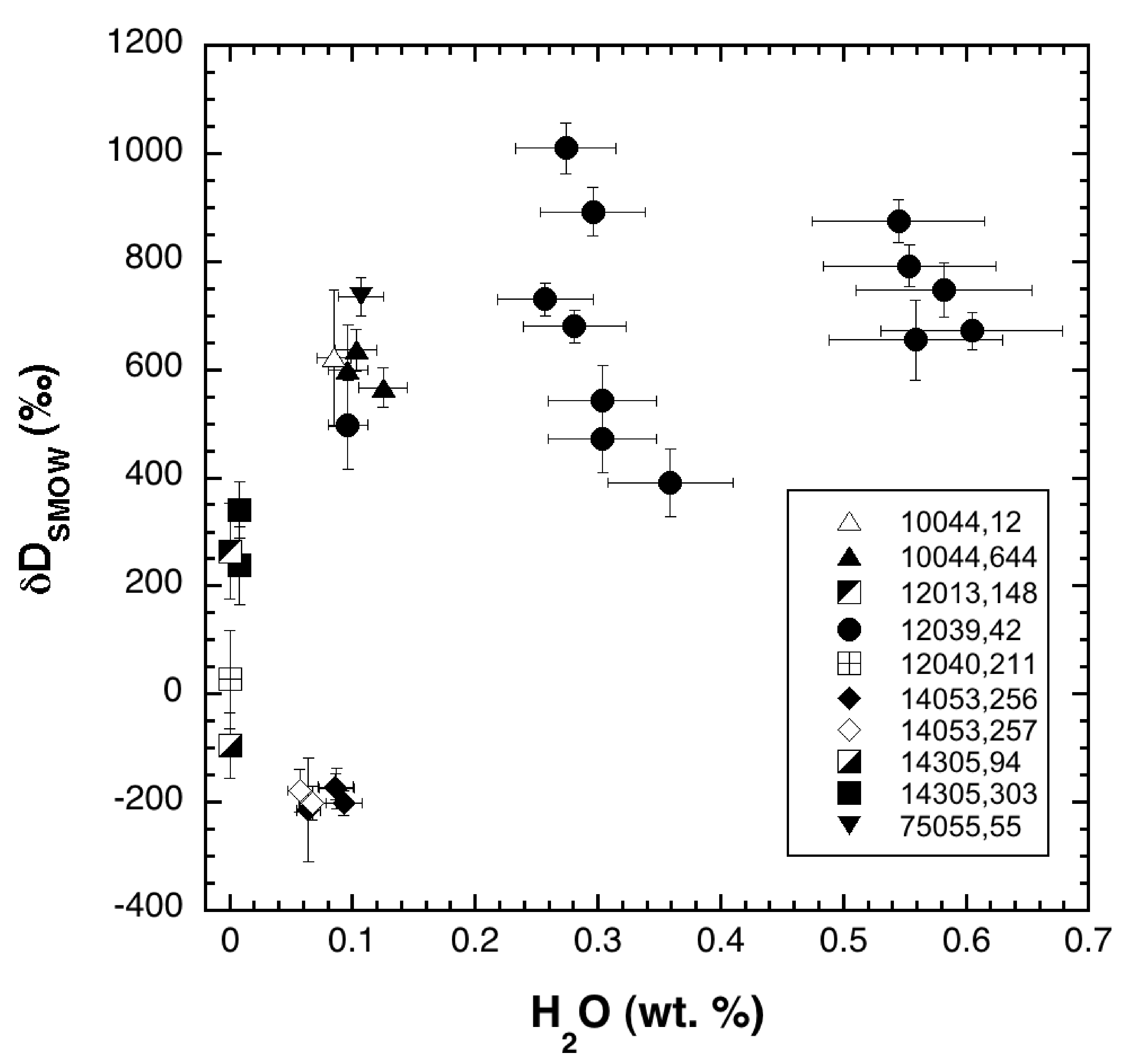




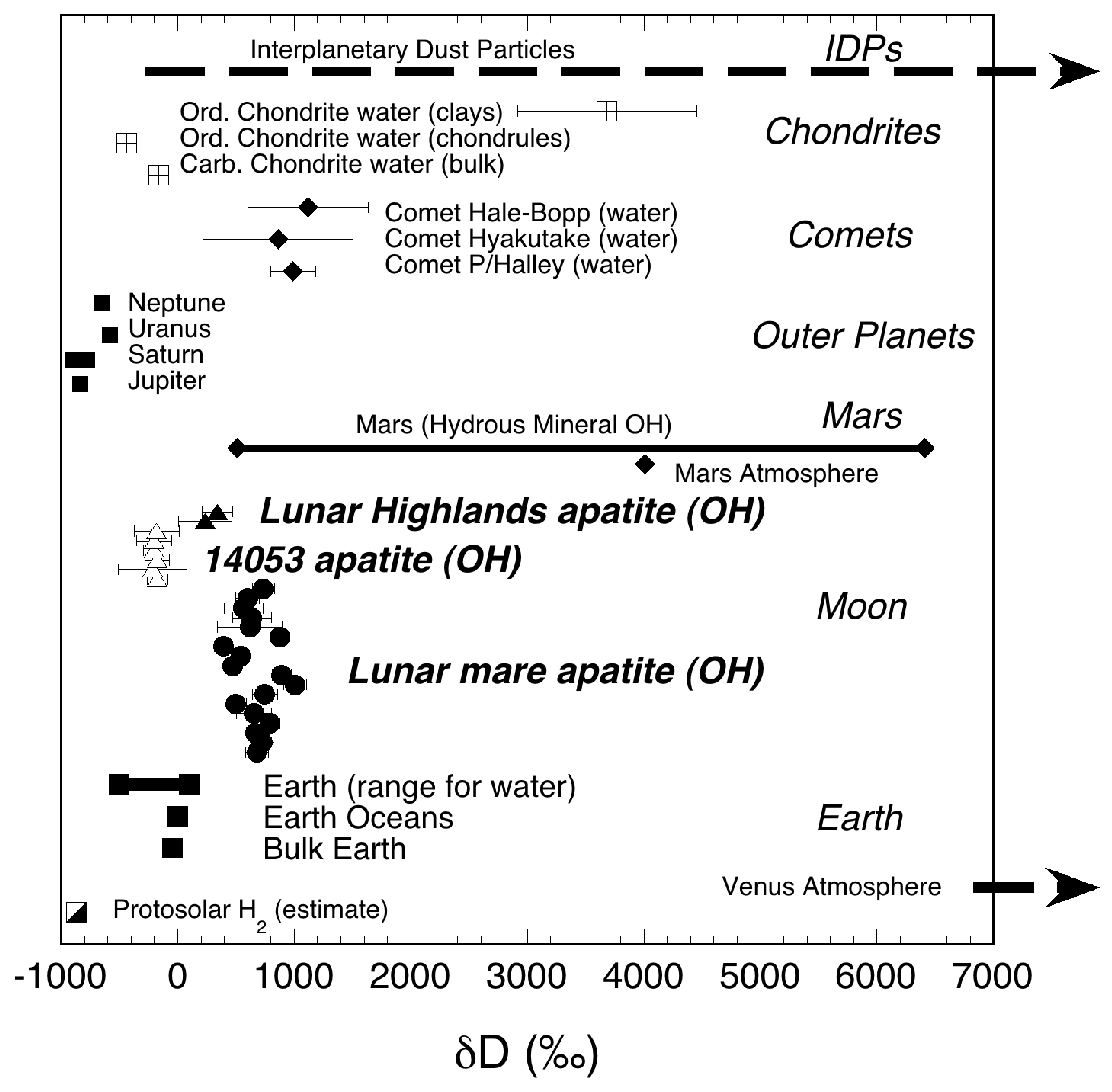

